\title{
Electrosynthesis of 3-Nitrophenotiazine. Nitration in Non-Aqueous Solutions
}

\author{
P.A. Perlo, M.N. Cortona, J.J. Silber and L.E. Sereno \\ Dpto de Química y Física, Universidad Nacional de Río Cuarto. Agencia Postal N: 3, 5800, Río \\ Cuarto, Argentina \\ E-mail: pperlo@exa.unrc.edu.ar
}

\begin{abstract}
The nitration of Phenothiazine (PHEN) in acetonitrile (ACN) in the presence of excess $\mathrm{NaNO}_{2}$ has been studied in detail. First, the electrochemical behavior of the reactants was investigated by cyclic voltammetry to determine the electrolysis conditions. Controlledpotential electrolysis was used for the electrosynthesis.
\end{abstract}

\section{Introduction}

Although the nitration of organic compounds is an area in expansion since the beginning of the century principles, its interest has not diminished. In this way, new nitration methods that outline new challenges for the interpretation of the mechanisms have appeared. The principal interest resides in that the nitrated products are fundamental source of diverse synthetic products [1-3]. The traditional nitration methods, which use aggressive mixtures of nitric and sulfuric acid, are being left, due to the high cost of the effluents treatment [4]. The electrochemical methods are an excellent way to produce the nitration intermediates [5]. Besides, it constitutes an interesting alternative procedure from the mechanistic point of view.

\section{Experimental}

An EG \& PAR model 273 potensiostat-galvanostat was used for cyclic voltammetry (CV) and controlled-potential electrolysis (CPE) measurements, using a conventional three-compartment Pyrex cell, stirring with a Teflon paddle for the EPC. The working electrodes were Pt wires of area $0.235 \mathrm{~cm}^{2}$ for $\mathrm{CV}$, and Pt electrodes of larger area $\left(\mathrm{ca} .16 \mathrm{~cm}^{2}\right)$ for CPE. The counter-electrode was a stainless steel foil of large area. All the potentials were referred to a saturated calomel electrode (SCE) and were corrected for $I R$ drop by positive feedback techniques.

The disappearance of the reagent and the consequent apparition of the nitrated product were followed by HPLC analyses. 3-Nitrophenotiazine (3- $\left.\mathrm{NO}_{2} \mathrm{PHEN}\right)$ was thermally synthesized as described in the literature [6]. 


\section{Results and Discussion}

CV studies shows that the oxidation of PHEN to proceed in two reversible one-electron steps, giving the radical cation $\mathrm{PHEN}^{+\bullet}$ and the dication $\mathrm{PHEN}^{++}$, respectively, peak $\mathrm{I}\left(\mathrm{E}_{\mathrm{pI}}=0.58 \mathrm{~V}\right)$ and peak II $\left(\mathrm{E}_{\mathrm{pII}}=1.00 \mathrm{~V}\right)$. Since for the electrosynthesis we are only interested in the generation of the $\mathrm{PHEN}^{+\bullet}$, the $\mathrm{CV}$ were registered until $0.8 \mathrm{~V}$. The peak current $\mathrm{I}_{\mathrm{pI}}$ shows a linear dependence on $\mathrm{v}^{1 / 2}$ in the range of sweep rates used (i.e. 0.01 to $0.3 \mathrm{~V} \mathrm{~s}^{-1}$ ) and $\mathrm{E}_{\mathrm{pI}}$ as well as $\Delta \mathrm{E}_{\mathrm{pI}}$ give a constant value on $\mathrm{v}$. This is the expected behavior for a fast diffusion controlled process. At the same potential, the ion $\mathrm{NO}_{2}{ }^{-}$is oxidized to $\mathrm{NO}_{2}$. Nevertheless, $\mathrm{CV}$ studies showed that the nitrated product is formed by the reaction between the $\mathrm{FEN}^{++}$(formed by desproportionation of $\mathrm{PHEN}^{+\bullet}$ and the $\mathrm{NO}_{2}{ }^{-}$ion

$\mathrm{CPE}$ was performed at $\mathrm{E}=0.5 \mathrm{~V}$. Several samples were taken to different times of electrolysis, following by HPLC the increase of the peak of the product ( $\tau=23 \mathrm{~min}$ ). A yield greater than $90 \%$ of 3$\mathrm{NO}_{2}$ PHEN was obtained under optimized conditions. A reaction mechanism is proposed.

Acknowledgements: Financial support from CONICET, CONICOR, FONCYT and the Secretaría de Ciencia y Técnica de la Universidad Nacional de Rio Cuarto is gratefully acknowledged. Patricia Perlo thanks CONICOR for a research fellowship.

\section{References and Notes}

1. Olah, G.A. Chemistry of Energetic Materials; Academic Press: New York, 1991; Cap. 7.

2. Ridd, J.H. Chem. Soc. Rev. 1991, 20, 149.

3. Eberson, L.; Radner, F. Acc. Chem. Res. 1987, 20, 53.

4. Smith; Musson, A.; DeBoos, G. A. Chem .Commun 1996, 469.

5. Laurent, A.; Laurent, E.; Locher, P. Electrochim. Acta 1975, 20.

6. Shine, H.J.; Silber, J.J.; Bussey, R.J.; Okuyama, T. J.Org Chem 1972, 37, 2697. 